\title{
Harmonic Compensation and Reactive Power Support Using Ultracapacitor with Shunt Active Filter in Distribution system
}

\author{
${ }^{1}$ A.Sathya Priyanka, Dr.A.Satheesh ${ }^{2}$ \\ ${ }^{I} P G$ Scholar, Nandha Engineering College, \\ ${ }^{2}$ Dean And HOD/EEE, NandhaEngineeringCollege
}

\begin{abstract}
Sustaining a quality of power supply is an important problems to the power Engineers. Owing to improvement in power quality a lot of power electronic devices and custom power devices are used in the industrial and commercial applications. Some of the non-linear loads and converters produces non-linear characteristics and create a flow of harmonic component in lines. Due to this effect, load voltages, load currents and the neutral current waveform due to unbalance gets distorted. In this project, the above effects are mitigated by neuro fuzzy Hysteresis Controller based ultracapacitor (UCAP) integration with an APF through a bi-directional $d c-d c$ converter with in the phase conductor. By connecting filter in the line, load voltage becomes nearly sinusoidal and the distortion in the load and neutral current is reduced significantly. The MATLAB/Simulink model is used to verify this method.

Index Terms: Neuro Fuzzy Logic, Hysteresis Controller, Phase Locked Loop, Active Filter, ultra capacitor (UCAP), Coupling Transformer.
\end{abstract}

\section{Introduction}

Ultra capacitor are made up of double layered electromechanical capacitors, have established a lot of considerations in power conversion application. They are widely used in controlled industrial electric drives, traction and automotive drives, uninterruptible power supplies (UPSs), and active filters. It energy storage devices and their advantages over the conventional capacitors and electrochemical batteries are high energy and power density, high efficiency, high cycling capability, and long life.

The ac power system has viewed the problems concerning reactive power and unbalance. It has deteriorated with the increased use of power electronic converters as some of these converters not only increase reactive currents, but also generate harmonics in the source current. These power electronic converters are used in variable frequency AC motor drives, large power supplies, standby inverters and UPS, battery chargers, etc., which produces harmonics with large harmonic ranges. The current quality problem also concerned under unbalance. The increased reactive power, harmonics, and unbalance cause an increase in line losses, instability, and voltage distortion when harmonics increases and produce voltage drop across the line impedance, which spoils the power system. Conventionally, shunt passive filers are used to suppress the harmonics, and also provides reactive power compensation.

An UCAP bank into a unified power quality conditioner (UPQC) system through dc-de converter is also providing active and reactive power support for the grid through the shunt APF is an another applications. The grids are connected with distributed energy sources through a three-phase grid-tied inverter which can be controlled to supplying active power, reactive power, harmonic compensation, and frequency regulation.

\section{Three-Phase Grid Connected Inverter}

A system diagram of the proposed system is shown in Fig. 1. The APF-UCAP is connected between the source and load with coupling transformer in shunt with the system. This system consists of a UCAP, bidirectional dc-dc converter which acts as an interface between the UCAP and the grid tied inverter. The advantage of this system is that, it has the capability to supply and absorb active power from the grid .In UCAP there will be some voltage profile changes during charges/discharges it can be controlled by bi-directional dc-dc converter while the inverter dc-link voltage has to stay constant for accurate control of inverter. Due this converter act as a boost converter while the UCAP is discharging energy into the grid and during charging the UCAP from the grid it acts as buck converter .

\section{A. Power Stage}

The power stage that consists of a three-phase inverter and its controller is shown in Fig. 2. This system includes of an insulated gate bipolar transistor (IGBT) module, its gate driver, LC filter, and an isolation transformer.The dc-link capacitor voltage has to be regulated for optimum performance of the converter such that

$\mathrm{V}_{\mathrm{dc}}=(2 \sqrt{2} \mathrm{n} / \sqrt{3} \mathrm{~m}) \operatorname{Vab}(\mathrm{rms})$ 
where $\mathrm{m}$ is the modulation index and $\mathrm{n}$ is the turns ratio of the isolation transformer. In this application for low-voltage distribution grids, the line-line rms voltage is $208 \mathrm{~V}, \mathrm{~m}$ is 0.75 , and $\mathrm{n}$ is $\sqrt{3}$ for the delta-wye transformer which yields the required dc-link voltage Vdc of $260 \mathrm{~V}$.

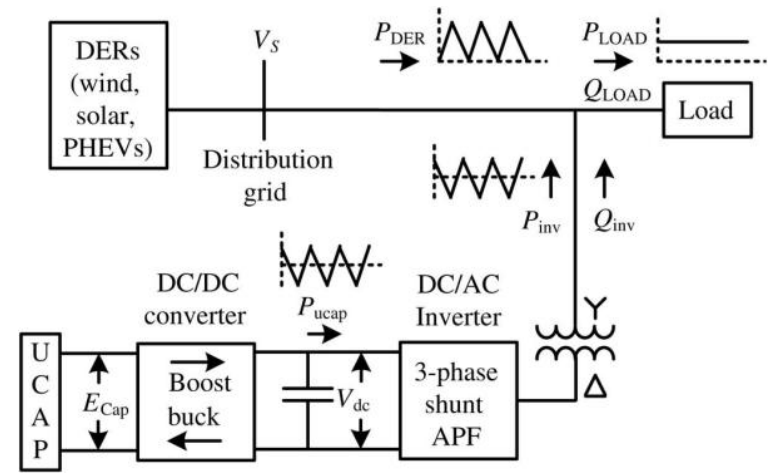

Fig. 1. Diagram of the APF-UCAP system.

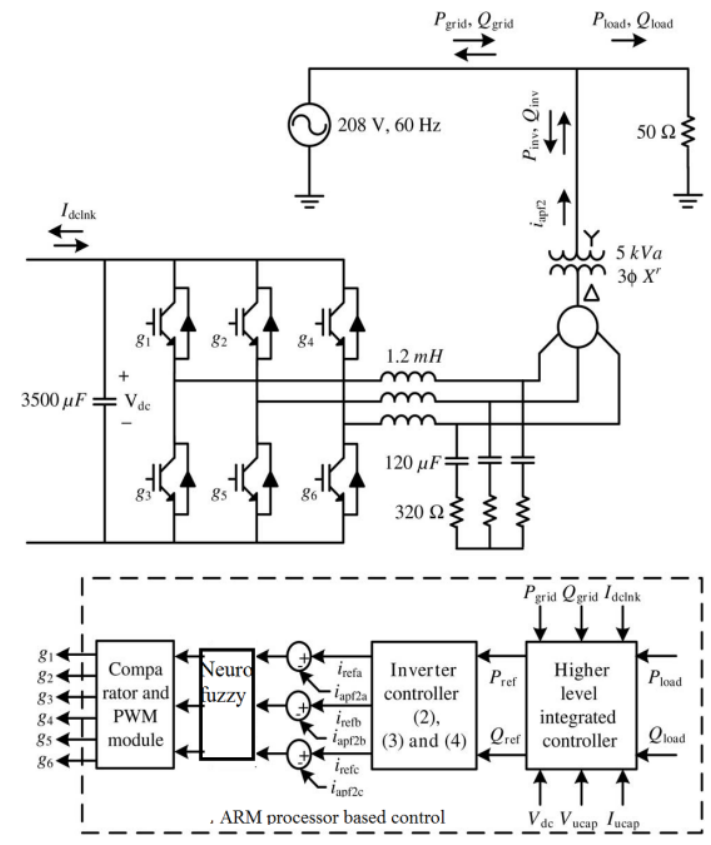

Fig. 2. Proposed Model of three-phase shunt APF and its controller.

\section{B. Controller Implementation}

To control the three-phase shunt APF to provide harmonic and reactive power compensation of which the most common approaches are the $p-q$ method [13], [14] and the $i_{d}-i_{q}$ method [15]. In [15], the authors state that the $i_{d}-i_{q}$ control performs better in nonsinusoidal and unbalanced conditions when compared to the $p-q$ method, while both methods perform in a similar manner in balanced sinusoidal conditions. In this system, the id-iq method is modified to provide active and reactive power compensation instead of the reactive and harmonic compensation described in [15] such that $i_{d}$ controls the reactive power and iq controls the active power [8]. Therefore, based on the references for active and reactive powers $P$ the reference currents iqref and idref in $\mathrm{d}$ - $\mathrm{q}$ domain can be calculated using (2) and (3), where $\mathrm{v}$ is the system voltage in q-domain. Ideally, a higher-level integrated controller will be determining the values of Pref, Qrefsq based on various system inputs like Pgrid, Qgrid, Pload, Qload, Vdc, Vucap and Idclnk as shown in Fig. 2

$P_{\text {ref }}=-3 / 2\left(v_{\text {sq }} i_{\text {qref }}+v_{\text {sd }} i_{\text {dref }}\right)$

If $\mathrm{v}_{\mathrm{sd}}=0$, then $\mathrm{P}_{\mathrm{ref}}=-3 / 2$ vsqiqref. Similarly,

$\mathrm{Q}_{\mathrm{ref}}=3 / 2\left(\mathrm{v}_{\mathrm{sd}} \mathrm{i}_{\text {qref }}-\mathrm{v}_{\mathrm{sq}} \mathrm{i}_{\text {dref }}\right)$ 
and if $\mathrm{v}_{\mathrm{sd}}=0$, then $\mathrm{Q}_{\mathrm{ref}}=-3 / 2\left(\mathrm{v}_{\mathrm{sq}} \mathrm{i}_{\text {dref }}\right)$

The reference currents in the $\mathrm{d}-\mathrm{q}$ domain can be trans-formed into the reference currents $\mathrm{i}_{\text {refa }}$, $\mathrm{i}_{\text {refb }}$, and $\mathrm{i}_{\text {refc }}$ in the $\mathrm{a}-\mathrm{b}$ - c domain using

$$
\left[\begin{array}{l}
i_{\text {refa }} \\
i_{\text {refb }} \\
i_{\text {refc }}
\end{array}\right]=\left[\begin{array}{rr}
1 & 0 \\
-\frac{1}{2} & \frac{\sqrt{3}}{2} \\
-\frac{1}{2} & -\frac{\sqrt{3}}{2}
\end{array}\right]\left[\begin{array}{rr}
\cos \theta & \sin \theta \\
-\sin \theta & \cos \theta
\end{array}\right]\left[\begin{array}{l}
i_{\text {dref }} \\
i_{\text {qref }}
\end{array}\right] .
$$

Equation (5) requires a phase-locked loop (PLL) to estimate the value of $\theta$ and the PLL used in this paper is based on the fictitious power method proposed in [14]. The main advantage of the fictitious power method is that it tracks the positive sequence voltage $\mathrm{V}+1$ instead of the actual system voltage which is very useful in unbalanced systems. Once the reference currents $i_{\text {refa }}, i_{\text {refb }}$, and $i_{\text {refc }}$ are calculated they are compared with the actual inverter currents $i_{\text {apf2a }}, i_{\text {apf } 2 b}$, and $i_{\text {apf2c }}$ and the error is passed through a neuro fuzzy logic controller. There are various methods for current control like hysteresis, sigma-delta and PI control. Among these neuro fuzzy control is the most stable; however, it requires the tuning of controller gains based on the system parameters.

The output frequency is controlled by reference voltage to maintain regulation. The frequency counter is used to sense the supply frequence( $\mathrm{Vabç}$ ). the supply frequency is compared with the reference frequency to obtain the error value. The compensated value is produced by the Neuro fuzzy controller and the compensated value is fed to the Phase Locked Loop (PLL). When the supply frequency is varied beyond the power quality limit, the frequency controlling system changes the required PLL from Neuro-fuzzy controller.The conventional control (PI), system is not suitable for non linear systems. ANN's is mostl used in the field of engineering as problem-solving tools. The fundamental element is a neuron which has multiple inputs and a single output. Each input is multiplied by a weight, the inputs are summed and this quantity is operated by the transfer function of the neuron to generate the output The output is sometimes referred to as an activity level.

\section{C.Higher Level Integrated Controller}

This controller is designed to make system level decisions on the inverter and dc-dc converter controller. The parameters like $\mathrm{P}_{\text {load, }} \mathrm{Q}_{\text {load }}, \mathrm{P}_{\text {grid }}, \mathrm{Q}_{\text {grid }}, \mathrm{V}_{\mathrm{ucap}}, \mathrm{V}_{\mathrm{dc}}, \mathrm{I}_{\mathrm{dclnk}}$, and $\mathrm{I}_{\text {ucap }}$ will decide on operating in four various modes. They are active power support mode, reactive power support mode, renewable intermittency smoothing mode, and UCAP charge mode.

\section{a) Active power support mode}

In both active power and renewable intermittency smoothing mode, the active power is supplied to the grid through UCAP-APF. Therefore, the active power capability of the UCAP-APF this can be evaluated by the higher level integrated controller. From the values of Pgrid and $\mathrm{P}_{\text {load }}$, the reference $\mathrm{P}_{\text {ref }}$ is calculated in the higher level integrated controller and the P ref command is used to decided the UCAP storage and discharging capacity. If it has enough capacity, dc-dc converter controller is functioned in Grid Support Mode otherwise it is operated in Charge Mode where the UCAP is recharged to support the system whenever it requires power. In Grid Support Mode ,bi-directional converter operate in both Buck and Boost modes to respond to the active power requests and to regulate the dc-link voltage in a stable fashion while the inverter controller should respond such that the inverter through current control is used to produce command $\mathrm{P}_{\text {ref. }}$

\section{b) Reactive power support mode}

In this mode the UCAP-APF system supplies reactive power to the grid and it does not provide any active power to the grid and even the APF losses are provided by the grid. From the values of $\mathrm{Q}_{\text {grid }}$ and $\mathrm{Q}_{\text {load }}$, the reference value $\mathrm{Q}_{\mathrm{ref}}$ is calculated in the integrated controller. In this mode, the $\mathrm{dc}$-dc converter controller can be programmed to operate in Grid Support Mode directly since the active power requirement for operating in this mode is minimal. Therefore, the dc-dc converter controller is to regulate the dc-link voltage in a stable, while the commanded Qref is supplied by the inverter through current control.

\section{c) Charge Mode}

In this mode the UCAP is recharged by absorbing active power from the grid when the charge falls under $50 \%$. The UCAP can be charged is controlled by the higher level integrated controller based on the $\mathrm{P}_{\text {grid }}$ and $\mathrm{P}_{\text {load }}$ values and the reference $\mathrm{P}_{\text {ref }}$ is calculated. The dc-dc converter will operate in Buck Mode to absorb the power from the grid then this operation is called charge mode and the inverter controller must respond to supply commanded $\mathrm{P}_{\text {ref. }}$ 


\section{Simulation Results}

The simulation of the system which includes the three-phase grid tied inverter and the dc-dc converter is performed using MATLAB/SIMULINK. The commanded reactive power supply is simulated with $\mathrm{i}_{\text {ref }}=-15 \mathrm{~A}$ which translates to a $\mathrm{Q}_{\text {dref }}$ of $3819 \mathrm{Var}$ from (3). The simulation results are shown in Fig. 3(a) and (b) where the UCAP is charged until $0.08 \mathrm{~s}$, at which point the UCAP voltage $\mathrm{E}_{\text {capv }}$ reaches a value of $144 \mathrm{~V}$. The UCAP is connected to the dc-dc converter at $t=0.10 \mathrm{~s}$. Att $=0.12 \mathrm{~s}$, the inverter is synchronized to the grid. It can be observed from Fig. 3(a) and (b) that $P_{\text {inv }}, Q_{\text {inv }}$, and $V_{\text {inv }}$ have converged to the steadystate values of $-92 \mathrm{~W}, 3570$ Var, and $260 \mathrm{~V}$, respectively, closely tracking the commanded $Q_{\text {ref. }}$ The inverter current and voltage waveforms when the system provides reactive power support are shown in Fig. 3(c) where it can be observed that $\mathrm{I}_{\text {refa }}$ tracks the reference current $\mathrm{I}_{\mathrm{apf2a}}$ accurately after synchronization with the grid and Iapf2a lags $\mathrm{V}_{\mathrm{sa}}$ by approximately 90 which is required for reactive power compensation. It can also be observed from voltage waveforms that the inverter voltage $\mathrm{V}_{\text {invla }}$ is almost sinusoidal after synchronization. The ability of the system to supply commanded active power is then simulated with $i_{\text {qref }}=12.0 \mathrm{~A}$ which translates to $\mathrm{P}_{\text {ref }}$ of $3054 \mathrm{~W}$ from (2). The simulation setup is the same as in the previous case and the simulation results are shown in Fig. 4(a) and (b) where it can be observed that Pinv, $\mathrm{Q}_{\mathrm{inv}}, \mathrm{V}_{\mathrm{fdc}}$, and $\mathrm{I}_{\text {dclnkav }}$ have converged to steady-state values of $2701 \mathrm{~W}, 466 \mathrm{Var}, 260 \mathrm{~V}$, and 10.82A closely tracking the commanded $\mathrm{P}_{\text {ref. }}$.

Similarly, the simulation results for the renewable inter-mittency smoothing applications where the UCAP must be capable of both supplying and absorbing active power are shown in Fig. 5(a) and (b). Since the results for the case where the UCAP and the inverter system supply active power to the grid are already presented in Fig. 4(a) and (b), so in Fig. 5(a) and (b) similar results are presented for the case where the UCAP and inverter system absorb active power from the grid which is achieved by commanding a positive iqref of $7 \mathrm{~A}$ which corresponds to a Pinv of $-1782 \mathrm{~W}$. It can be observed from Fig. 5(a) and (b) that $\mathrm{P}_{\text {ref }}$, and $\mathrm{I}_{\text {dclnkav }}$ have converged to steady-state values of $-1791 \mathrm{~W}, 260 \mathrm{~V}$, and $-6.906 \mathrm{~A}$ again tracking the commanded P closely. It should also be noted that simulation results are presented for shorter time span when compared to hardware results due to limitations in MATLAB/SIMULINK software. Therefore, it is evident from the simulations that the UCAP and APF system can together respond to changes in $i_{\text {qref }}$ and $i_{\text {dref }}$ commands and accordingly provide active and reactive power support to the grid. It is also evident that both the dc-dc converter and inverter can operate in a bi-directional fashion which is necessary when the system is used in renewable intermittency smoothing applications.

In this paper, the UCAP with APF design which provides active power support, reactive power support, and renewable intermittency smoothing to the low voltage distribution grid. The UCAP with the APF provides active power capability. The control strategy of the inverter which is a modified version of the $i_{d}-i_{q}$ method is ideal for supplying as well as absorbing the commanded active or reactive power to the grid. Major component like bi-directional dc-dc converter are also implemented to control UCAP and to maintain power flow . The dc-dc converter is controlled by average current mode control to regulate ouput voltage of converter due to its inherently stable characteristic. A higher level integrated controller which takes decisions based on the system parameters provides inputs to the inverter and $\mathrm{dc}-\mathrm{dc}$ converter controllers to carry out their control actions
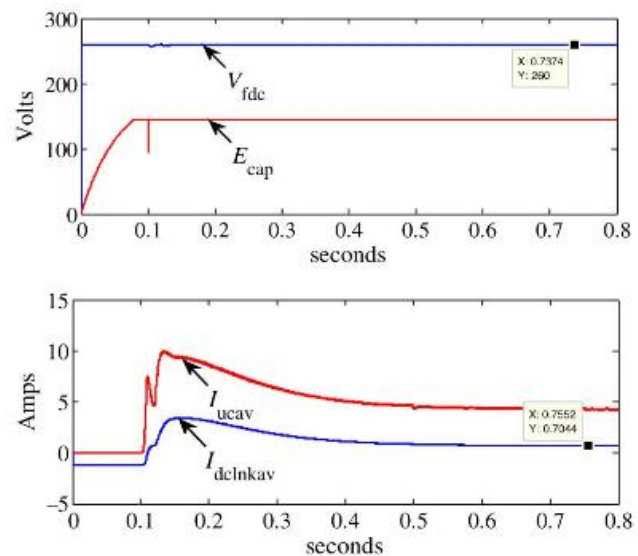

(a) 

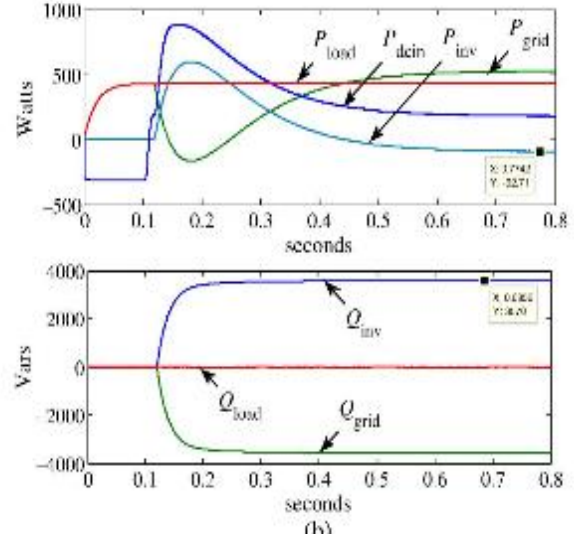

(b)
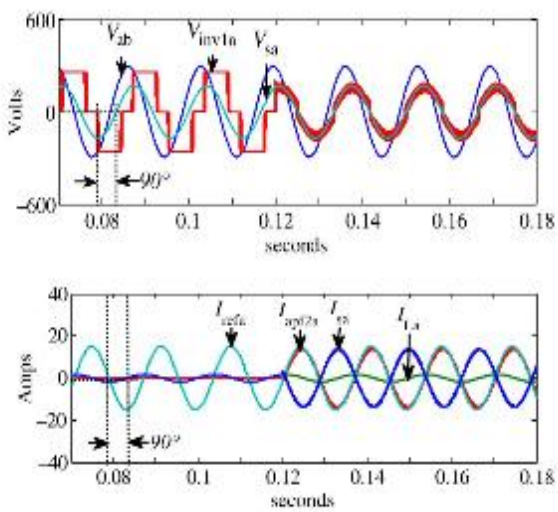

(c)

Fig. 3. (a) Currents and voltages of bi-directional $d c-d c$ converter for $i_{\text {dref }}=-15 \cdot 0 \mathrm{~A}$ (reactive power support). (b) Grid, load, and inverter active and reactive power curves for $i_{\text {dref }}=-15.0 \mathrm{~A}$ (reactive power support).(c) Currents and voltages of the inverter, grid, and load for idref $=-15.0 \mathrm{~A}$ (reactive power support).
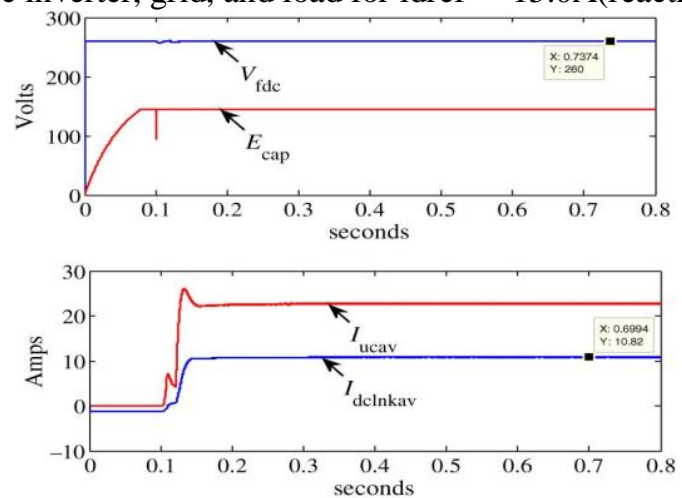

(a)
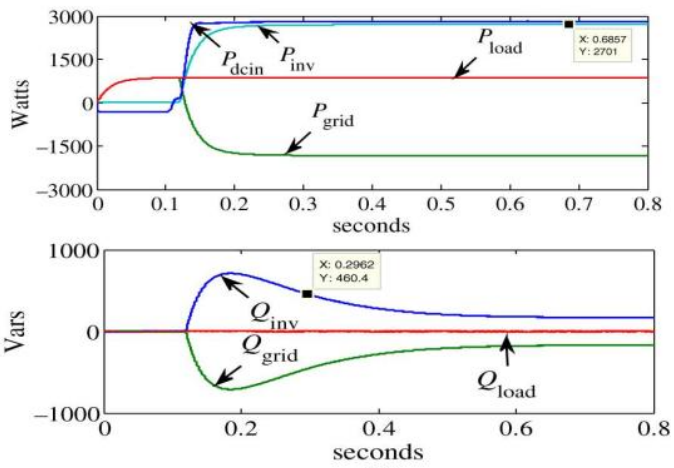

(b)

Fig. 4. (a) Currents and voltages of bi-directional dc-dc converter for $i_{\text {qref }}=-12.0 \mathrm{~A}$ (active power support). (b) Grid, load, and inverter active and reactive power curves for $\mathrm{i}_{\text {qref }}=-12.0 \mathrm{~A}$ (active power support; discharging active power). 


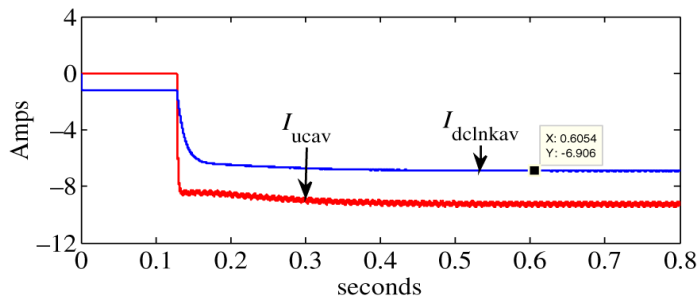

(a)

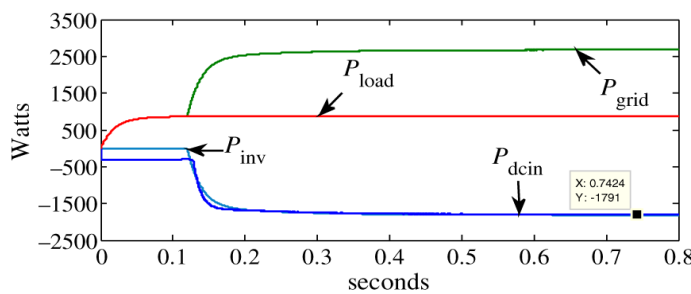

(b)

Fig. 5. (a) Currents of bi-directional dc-dc converter for $i_{\text {qref }}=7.0 \mathrm{~A}$ (renewable intermittency smoothing; absorbing active power). (b) Grid, load,and inverter active power curves for $i_{\text {qref }}=7.0 \mathrm{~A}$ (renewable intermittency smoothing; absorbing active power).

\section{Conclusion}

The simulation of the integrated system which consists of the UCAP, bi-directional dc-dc converter, and the grid-tied inverter is carried out using MATLAB/SIMULINK. Hardware experimental setup of the same integrated system is also possible to provide active power support, reactive power support and renewable intermittency smoothing to the distribution grid is dynamically tested through simulation.

\section{References}

[1]. P. F. Ribeiro, B. K. Johnson, M. L. Crow, A. Arsoy, and Y. Liu, "Energy storage systems for advanced power applications," Proc. IEEE, vol. 89,no. 12, pp. 1744-1756, Dec. 2001

[2]. M. Branda, H. Johal, and L. Ion, "Energy storage for LV grid support in Australia," in Proc. IEEE Innov. Smart Grid Technol. Asia (ISGT), Nov. 13-16, 2011, pp. 1-8.

[3]. A. B. Arsoy, Y. Liu, P. F. Ribeiro, and F. Wang, "StatCom-SMES," IEEE Ind. Appl. Mag., vol. 9, no. 2, pp. 21-28, Mar. 2003

[4]. K. Sahay and B. Dwivedi, "Supercapacitor energy storage system for power quality improvement: An overview," J. Elect. Syst., vol. 10 , no. 10 , pp. $1-8,2009$.

[5]. W. Li, G. Joos, and J. Belanger, "Real-time simulation of a wind turbine generator coupled with a battery supercapacitor energy storage system,” IEEE Trans. Ind. Electron., vol. 57, no. 4, pp. 1137-1145, Apr. 2010.

[6]. M. Ortuzar, J. Moreno, and J. Dixon, "Ultracapacitor-based auxiliary energy system for an electric vehicle: Implementation and evaluation,” IEEE Trans. Ind. Electron., vol. 54, no. 4, pp. 2147-2156, Aug. 2007.

[7]. Y. Chen and K. Smedley, “Three-phase boost-type grid-connected inverter,” IEEE Trans. Power Electron., vol. 23, no. 5, pp. 23012309, Sep. 2008

[8]. M. Chincilla, S. Arnalte, J. C. Burgos, and J. L. Rodriguez, "Power limits grid-connected modern wind energy systems," Renew. Energy, vol. 31, no. 9, pp. 1455-1470, Jul. 2006.

[9]. L. H. Walker, "10-MW GTO converter for battery peaking service,” IEEE Trans. Ind. Appl., vol. 26, no. 1, pp. 63-72, Feb. 1990.

[10]. D. Casadei, G. Grandi, and C. Rossi, "A supercapacitor-based power conditioning system for power quality improvement and uninterruptible power supply," in Proc. IEEE Conf. Ind.Electron., 2002, vol. 4, pp. 1247-1252.

[11]. M. E. Ortuzar, R. E. Carmi, J. W. Dixon, and L. Moran, "Voltage-source active power filter based on multilevel converter and ultracapacitor DC link," IEEE Trans. Ind. Electron., vol. 53, no. 2, pp. 477-485, Apr. 2006.

[12]. B. M. Han and B. Bae, "Unified power quality conditioner with supercapacitor for energy storage," Eur. Trans. Electr. Power, vol. 18, pp. 327-343, Apr. 2007.

[13]. H. Akagi, Y. Kanazawa, and A. Nabae, "Instantaneous reactive power compensators comprising switching devices without energy storage components,” IEEE Trans. Ind. Appl., vol. IA-20, no. 3, pp. 625-630, May 1984.

[14]. [14] H. Akagi, E. H. Watanabe, and M. Aredes, Instantaneous Reactive Power Theory and Applications to Power Conditioning, 1st ed. Hoboken, NJ, USA: Wiley, 2007.

[15]. [15] V. Soares, P. Verdelho, and G. D. Marques, "An instantaneous activand reactive current component method for active filters," IEEE Trans. Power Electron., vol. 15, no. 4, pp. 660-669, Jul. 2000.

[16]. B. Singh, V. Verma, and J. Solanki, "Neural network based selectivcompensation of current quality problems in distribution system,” IEEE Trans. Ind. Electron, vol. 57, no. 1, pp. 53-60, Feb. 2007.

[17]. J. R. Miller and A. F. Burke, "Electrochemical capacitors: Challenges and opportunities for real world applications," Electrochem. Soc. Interface, vol. 17, pp. 53-57, 2008.

[18]. P. J. Grbovic, P. Delarue, P. Le Moigne, and P. Bartholomeus, “A bidirectional

[19]. three-level dc-dc converter for the ultracapacitor applications,IEEE Trans. Ind. Electron., vol. 57, no. 10, pp. 3415-3430, Oct. 2010.

[20]. G. Ma et al., "A zero-voltage-switching bidirectional dc-dc converter with state analysis and soft-switching-oriented design consideration,IEEE Trans. Ind. Electron., vol. 56, no. 6, pp. 2174-2184, Jun. 2009. 